\title{
Effect of Immediate Implementing A Standardized Nursing Care, on Outcomes of patients With Acute Angle Closure Glaucoma
}

\author{
Mona N. Rashed, Ehab Ismail Wasfi, Mona Aly Mohammed \& Mogedda M. Mehany. \\ Clinical Nurse Specialist at Assiut Ophthalmic Hospital, Assiut, Egypt \\ Assistant Professor of Ophthalmology, Faculty of medicine, Assiut University, Egypt. \\ Assistant Professor of Critical Care Nursing, Faculty of Nursing, Assiut University, Egypt. \\ Assistant Professor of Critical Care Nursing, Faculty of Nursing, Assiut University, Egypt.
}

\begin{abstract}
Background: Acute angle closure glaucoma (AACG) is a true medical emergency. Glaucoma is the second leading cause of blindness worldwide. Aim: To assess the effect of immediate implementing standardized nursing care on outcomes of patients' with AACG. Methods: Quasi-experimental research design was used to conduct this study. The sample size calculated about 40 cases for each group include in the study. Data was collected using two tools Tool (1):- Patient assessment sheet. Tool (II):- Manifestations Assessment sheet. Results: There was a statistically significant difference before and immediately after implementing a standardized nursing care on patients outcomes with AACG regarding intra ocular pressure (P-value10.806, 0.124, 0.147), visual acuity and pain score among the studied groups p-value $(0.002,0.023$, and 0.001$)$ respectively. $65.0 \%$ of the studied groups had satisfactory level of knowledge regarding visual acuity, intra ocular pressure (IOP), and pain score characteristics. Conclusion Implementing a standardized nursing care had a positive effect on outcomes of patients' with AACG. Recommendations: Screening all people aged 40 years or more for symptoms \&signs of glaucoma. Health education programs about standardized nursing care rules for patients' with AACG.
\end{abstract}

\section{Keywords: Acute Angle Closure Glaucoma (AACG),Standardized Nursing Care, Intra Ocular Pressure (IOP), Visual Acuity \& Pain Score.}

\section{Introduction}

Acute angle closure glaucoma (AACG) is a true medical emergency. Rapid and immediate treatment is necessary to prevent optic nerve damage and permanent loss of vision, which can occur within hours without prompt and appropriate treatment (Dahl 2013).

Angel closure refers to occlusion of the trabecular meshwork by the peripheral iris -iridotrabecular contact (ITC), obstructing aqueous outflow. Primary angle closure glaucoma (PACG) is a condition in which elevation of intra ocular pressure (IOP) occurs as a result of obstruction of aqueous outflow by partial or complete closure of the angle by the peripheral iris (Heiting 2010).

Angle closure glaucoma (ACG)-iridotrabecular contact is present in three or more quadrants of the drainage angle in the presence of documented optic nerve damage. Secondary angle closure is caused by an underlying identifiable pathologic etiology, such as neovascularization or uveitis. If angle closure results in elevated IOP that causes glaucomatous optic disc damage. Both primary and secondary angle closure can result in acute angle closure attacks and chronic angle closure leading to glaucoma(Kanski 2013).

According to the Egyptian Society for glaucoma disease, incidence of glaucoma in Egypt about 0.5\% to $1 \%$ of the total population. In Egypt, more than half million of the children and adolescents are estimated to be affected by glaucoma (Egyptian Society for glaucoma disease, 2011).

Acute angle closure crises is characterized by sudden ocular pain, headaches, inflamed eye, cloudy cornea, seeing halos around lights, red eye, very high intraocular pressure $(>30 \mathrm{mmHg})$, nausea and vomiting, sudden decreased vision, and a fixed, middilated pupil (Allison et al. 2013).

Screening patients at greatest risk for angle closure can be beneficial in reducing the number of patients who develop these diseases and in reducing the risk of blindness (Freedman\& Steven 2012).

Treatment depends on the type of glaucoma. Acute angle-closure attack of glaucoma is a medical emergency; the patient can become blind in few days if not treated. The goal of treatment is to reduce eye pressure. Some people also need an emergency operation, called an iridotomy (Tasman \& Jueger.2013) \& (Ahmed, 2014).

Outcomes after AACG are dependent on duration from onset of the attack to start of treatment, underlying ocular disease, and ethnicity. The degree of IOP elevation has been shown to have less impact on future visual acuity (Chen et al., 2010). 
Critical care Nurses play a key role in the detection and prevention of acute angle closed glaucoma. Nurses are responsible for prevention of acute angle closed glaucoma by proper assessment, health teaching, and prevention measures .Nurses adherence to these measures will help reduce the incidence and potentially life- threatening implications (Attia et al; 2010).

\section{Significance of the study}

The Worldwide prevalence of primary acute closure glaucoma (PACG) among persons aged 40 years and older was estimated to be $0.69 \%$ in 2010, The number of people with PACG in the world was estimated to be over 15 million in 2010 (compared with >44 million for POAG), according to the Statistics of the Egyptian out patients' clinic at Ophthalmic Hospitals in Assuit (2013) the number of patients admitted to outpatient clinic was 40 patients (Hospital records of Ophthalmic Hospitals,2013). While the number of patients admitted to ophthalmic outpatient clinic was 40 patients atAssuit University Hospital (Assuit University Hospital records,2013).

\section{Aim of the study}

The aim of the study was to assess the effect of immediate implementing a standardized nursing care on outcomes of patients' with "Acute angle-closure glaucoma in ophthalmic outpatient' clinic at Assiut University Hospital and ophthalmic outpatient clinic of eye Hospital, Assiut Egypt.

Research question

- What is the effect of immediate implementing a standardized nursing care onoutcomes of patients' with "Acute angle-closure glaucoma?

\section{Subjects and methods}

\section{Research design}

Quasi -experimental research design was used to conduct this study.

\section{Setting of the study}

This study was carried out in ophthalmic outpatient clinic at Assuit University Hospital (40 cases) and ophthalmic outpatient clinics of ophthalmic Hospital (40 cases).

\section{Sample size}

The sample size was calculated using the EPI info 2000 statistical package. The calculation was done using the expected frequencies of outcome from previous studies using $95 \%$ confidence interval and $80 \%$ power of the test. The sample size calculated according to the above criteria was 40 cases for each study group.

Inclusion criteria
The study included all patients presented to eye emergency clinic with signs \& symptoms of acute angel closure glaucoma (AACG).

Exclusion criteria

- Presence of cataracts that cause low visual acuity or index-myopia.

- Secondary glaucoma e.g. uveitis, traumatic.

- Plateau iris.

Tools

Two tools were used by the researcher in this study after reviewing the related literatures.

Tool one: - Interview Questionnaire sheet:

This tool was used to assess patient condition, it was developed by the researcher based on review of the relevant related to literatures, this questionnaire composed of five parts as following :(Shojania et al, 2010, Green, 2011).

Part I: Demographic data:

Patients demographic data as age, sex, and level of education, marital status, and occupation.

Part II: Clinical data as:

Date of admission, date of discharge, medical diagnosis, history of the present illness, past medical diagnosis and medication administration sheet which include (drug's name, dose, frequency, and duration).

Part III: Assessment of homodynamic state:

This part was used to assess patients' hemodynamic state including (temperature, respiratory rate, pulse, and mean arterial blood pressure (ABP).

Part IV: Laboratory investigations:

It includes the result of the conjunctival smear, blood sugar;prothrombin time and Elisa test for virus $\mathrm{C}$ as all are ordered for each patient preoperatively.

Part V

It includesassessment of the participants regarding their knowledge in relation to the definition of acute angle closure glaucoma, risk factors, signs and symptoms, diagnosis.....etc. (pretest).

Tool two: Manifestations Assessment sheet:-Which consist of 4 parts

Part I: Assessment of manifestations for acute closed angle glaucoma:

It includes feeling of pain, severe headache, eye redness, blurred or reduced vision, nausea, and vomiting.

Part II:-Blurred vision (rapidly progressing to visual loss):

It includes assessing the visual acuity: by using snellen chart or lighted screen. It includes assessingvisual acuity by using (Light perception, Hand moving, Counting fingers, 6/60, 6/36, 6/12, 6/9)

Part III: Pain within and around the eye:

It includes assessingpain within and around the eye using visual analog scale (VAS), (0 No pain, 1-3 Mild pain, 4-6 Moderate pain, 7-10 Severe pain) and 
also by using the Numerical rating scale (NRS) (Nicol2012).

Part IV: Intraocular pressure (IOP) assessment: Tonometry: This test uses an instrument to measure the pressure inside the eyes by the researcher and doctor. Using the numbing drops applied by professional before performing this testNormal pressures range from 10 to $22 \mathrm{~mm} \mathrm{Hg}$, while glaucoma patients can measure over $22 \mathrm{~mm} \mathrm{Hg}$.

\section{Methods}

The study was conducted throughout three main phases, which are preparatory phase, implementation phase and evaluation phase.

\section{Preparatory phase for both groups}

- Seeking official permission to carry out the study was obtained from the hospital responsible authorities in Ophthalmology department after explaining the aim and nature of the study.

- The developed tools were tested for reliability.

- Revision of content validity by five panels of critical care medical and nursing experts.

- A pilot study was carried out in order to assess the feasibility and applicability of the tools and the necessary modifications were done. The pilot study was done on patients who will be included in the study, no major modification in the study tools were needed so patients in the pilot study were included in the study subjects.

\section{Ethical considerations}

- Research proposal was approved from Ethical Committee in the Faculty of NursingAssuitUniversity.

- There is no risk for study subject during application of the research.

- The study was following common ethical principles in clinical research.

- Written consent was obtained from patients' or guidance who willing to participate in the study, after explaining the nature and purpose the study.

- Patients were assured that the data collected will be used only for the purpose of the study.

- Confidentiality of the collected data.

- Patients have the right to refuse to participate andlor withdraw from the study without any rational and at any time.

\section{Implementation phase}

Data collection

Data were collected using direct face-face interview with "Acute angle-closure glaucoma patients.

\section{The assessment phase}

During this phase the researcher assessed patient from the first day of admission and recorded patient's bio-demographic data and clinical data as wellusing tool 1 (part 1).
- The researcher assessed the homodynamic state of patient, and documented the result of the laboratory investigations using tool 1(part 3,4).

- The researcher assessed each patient's eye and the ability of the patient to maintain acute angle closure glaucoma to determine degree of pain within and around the eye, visual loss, nausea and vomiting, red eye, headache, papillary edema by using tool 2 (part1-6).

- The assessment stage of the study sample of AACG done allover six months period.

- The data collected from the first day ofpatients' admission (base line data),thenevery 8 hours and recorded in the developed tools.

- The study sample included all patients admitted in eye emergency clinic at Assuit University Hospital and ophthalmic Hospital.

- The researcher monitor pain as an indicator for increased intraocular pressure, as well as sensory perceptual alteration for vision in relation toincreased intraocular pressure and decreased visual acuity.

\section{The intervention phase}

During this phase patients also were assessed pre intervention andreceived thestandardized nursing care as the following

1. The researcher gave medications according to doctor order, providing no contraindications exist: One drop of timolol0.5\%, One drop of pilocarpine $2 \%, 500 \mathrm{cc}$ acetazolamide orally and the clinician should check intraocular pressure readings every 15-30 minutes.

2. If the attack is not broken, 1 hour after the institution of the treatment, oral hyperosmotic, ex: $50 \%$ glycerin dose of $1.5 \mathrm{ml} / \mathrm{kg}$ body weight, metabolized, $45 \%$ isosorbide, may be administered along with repeating all the topical medications.

3. When the Intraocular pressure falls to $20 \mathrm{~mm} \mathrm{Hg}$ or below, gonioscopy should performed to confirm that the angle is open.

4. When the attack could be broken medically, the patient should maintain on $2 \%$ pilocarpine four times a day bilaterally, and $1 \%$ prednisolone acetate four times daily in the affected eye until a laser peripheral iridotomy is performed until they have YAG laser peripheral iridotomy.

\section{The evaluation phase}

The evaluation was done through:

Each patient evaluated three times: on admission, and every 2 hrs.after admission until discharge. This phase will be done to evaluate the outcome of theimmediate standardized nursing care for patients with "Acute angle-closure glaucoma. The evaluation was done using the same tools (I, II,) for study sample. This phase was evaluated based on the 
assessment of the visual acuity by using snellen chart, Patients verbalizes eye pain relief or modified by using visual analog scale (VAS), Cessation of vomiting and normal vital signs according to patient's baseline.(Normal Intra Ocular Pressure $20 \mathrm{mmhg}$ )

(Green, 2011).

\section{Statistical analysis}

Data were computerized and analyzed by Computer program SPSS (ver16). Data were presenting by using descriptive statistics in the form of frequencies and percentage or means \pm standard deviations for qualitative data. Quantitative data were comparing using Independent samples t- test for comparisons between two groups. Quantitative variables were comparing using Chi-square and exactly fissure test to determine significance. The critical value of the tests "p" was considered statistically significant when P-values were less than 0.05 .

\section{Results}

Table (1): Demographic characteristics of the studied groups at" both hospitals, 2014".

\begin{tabular}{|c|c|c|c|c|c|}
\hline \multirow[t]{2}{*}{ Variables } & \multicolumn{2}{|c|}{$\begin{array}{c}\text { MOH } \\
(n=40)\end{array}$} & \multicolumn{2}{|c|}{$\begin{array}{c}\text { AUH } \\
(n=40)\end{array}$} & \multirow[t]{2}{*}{ P-value } \\
\hline & No. & $\%$ & No. & $\%$ & \\
\hline \multicolumn{5}{|l|}{ Age:(years) } & \multirow{3}{*}{0.485} \\
\hline$<60$ years & 16 & 40.0 & 13 & 32.5 & \\
\hline$\geq 60$ years & 24 & 60.0 & 27 & 67.5 & \\
\hline \multicolumn{5}{|l|}{ Sex: } & \multirow{3}{*}{0.260} \\
\hline Male & 20 & 50.0 & 15 & 37.5 & \\
\hline Female & 20 & 50.0 & 25 & 62.5 & \\
\hline \multicolumn{5}{|l|}{ Marital status } & \multirow{5}{*}{0.162} \\
\hline Single & 4 & 10.0 & 0 & 0.0 & \\
\hline Married & 30 & 75.0 & 33 & 82.5 & \\
\hline Widowed & 6 & 15.0 & 6 & 15.0 & \\
\hline Divorced & 0 & 0.0 & 1 & 2.5 & \\
\hline \multicolumn{5}{|l|}{ Level of education } & \multirow{6}{*}{0.167} \\
\hline Illiterate & 32 & 80.0 & 23 & 57.5 & \\
\hline Read \& write & 5 & 12.5 & 10 & 25.0 & \\
\hline Basic education & 2 & 5.0 & 2 & 5.0 & \\
\hline Secondary & 1 & 2.5 & 2 & 5.0 & \\
\hline University & 0 & 0.0 & 3 & 7.5 & \\
\hline \multicolumn{5}{|l|}{ Residence } & \multirow{3}{*}{$0.043 *$} \\
\hline Rural & 38 & 95.0 & 32 & 80.0 & \\
\hline Urban & 2 & 5.0 & 8 & 20.0 & \\
\hline \multicolumn{5}{|l|}{ Occupation } & \multirow{4}{*}{0.103} \\
\hline Unemployed & 36 & 90.0 & 29 & 72.5 & \\
\hline Employer & 2 & 5.0 & 3 & 7.5 & \\
\hline Retired & 2 & 5.0 & 8 & 20.0 & \\
\hline \multicolumn{5}{|l|}{ Having health insurance } & \multirow{3}{*}{0.176} \\
\hline Have health insurance & 3 & 7.5 & 7 & 17.5 & \\
\hline Have not health insurance & 37 & 92.5 & 33 & 82.5 & \\
\hline
\end{tabular}

Ns: No Statistically significant difference $(p>0.1) *$ statistically significant difference $(p<0.1)$

"Both hospitals": Ministry Ophthalmic of Health Hospital (MOH) and Assist University hospital (AUH). 
Table (2):Distribution of the studied groups with AACGregarding pain score.

\begin{tabular}{|c|c|c|c|}
\hline Pain score & $\begin{array}{c}\text { MOH } \\
(n=40)\end{array}$ & $\begin{array}{c}\text { AUH } \\
(n=40)\end{array}$ & P-value ${ }^{1}$ \\
\hline \multicolumn{3}{|l|}{ At admission } & \multirow{3}{*}{0.791} \\
\hline Mean \pm SD & $7.78 \pm 1.40$ & $7.85 \pm 1.10$ & \\
\hline Range & $5-10$ & $5-10$ & \\
\hline \multicolumn{3}{|c|}{ After $6 \mathrm{hrs}$ from admission } & \multirow{4}{*}{0.800} \\
\hline Mean \pm SD & $5.08 \pm 1.53$ & $5.15 \pm 1.08$ & \\
\hline Range & $3-8$ & $3-8$ & \\
\hline$P$-value ${ }^{2}$ & $0.000^{*}$ & $0.000^{*}$ & \\
\hline \multicolumn{3}{|l|}{ At discharge } & \multirow{4}{*}{0.913} \\
\hline Mean \pm SD & $2.35 \pm 1.12$ & $2.33 \pm 0.92$ & \\
\hline Range & $1-5$ & $1-4$ & \\
\hline$P$-value ${ }^{3}$ & $0.000 *$ & $0.000 *$ & \\
\hline
\end{tabular}

Ns: No Statistically significant difference $(p>0.1) *$ statistically significant difference $(p<0.1)$

Table (3): Distribution of the studied group's according to visual acuity atdischarge about acute angle closure glaucoma at both hospitals, 2014.

\begin{tabular}{|c|c|c|c|c|c|c|c|c|c|c|}
\hline \multirow{3}{*}{ Visual acuity } & \multicolumn{4}{|c|}{ MOH } & \multirow{3}{*}{ P-value } & \multicolumn{4}{|c|}{ AUH } & \multirow{3}{*}{ P-value } \\
\hline & \multicolumn{2}{|c|}{ Pre-test } & \multicolumn{2}{|c|}{ Post-test } & & \multicolumn{2}{|c|}{ Pre-test } & \multicolumn{2}{|c|}{ Post-test } & \\
\hline & No. & $\%$ & No. & $\%$ & & No. & $\%$ & No. & $\%$ & \\
\hline Light perception & 5 & 12.5 & 3 & 7.5 & 0.712 & 7 & 17.5 & 3 & 7.5 & 0.176 \\
\hline Hand moving & 9 & 22.5 & 4 & 10.0 & 0.130 & 10 & 25.0 & 5 & 12.5 & 0.152 \\
\hline Counting fingers & 15 & 37.5 & 3 & 7.5 & $0.001^{*}$ & 13 & 32.5 & 2 & 5.0 & $0.002 *$ \\
\hline $6 / 60$ & 6 & 15.0 & 1 & 2.5 & 0.108 & 5 & 12.5 & 1 & 2.5 & 0.201 \\
\hline 6/36 & 2 & 5.0 & 9 & 22.5 & $0.023^{*}$ & 2 & 5.0 & 9 & 22.5 & $0.023^{*}$ \\
\hline 6/12 & 3 & 7.5 & 15 & 37.5 & $0.001 *$ & 3 & 7.5 & 16 & 40.0 & $0.001 *$ \\
\hline $6 / 9$ & 0 & 0.0 & 5 & 12.5 & 0.055 & 0 & 0.0 & 4 & 10.0 & 0.116 \\
\hline
\end{tabular}

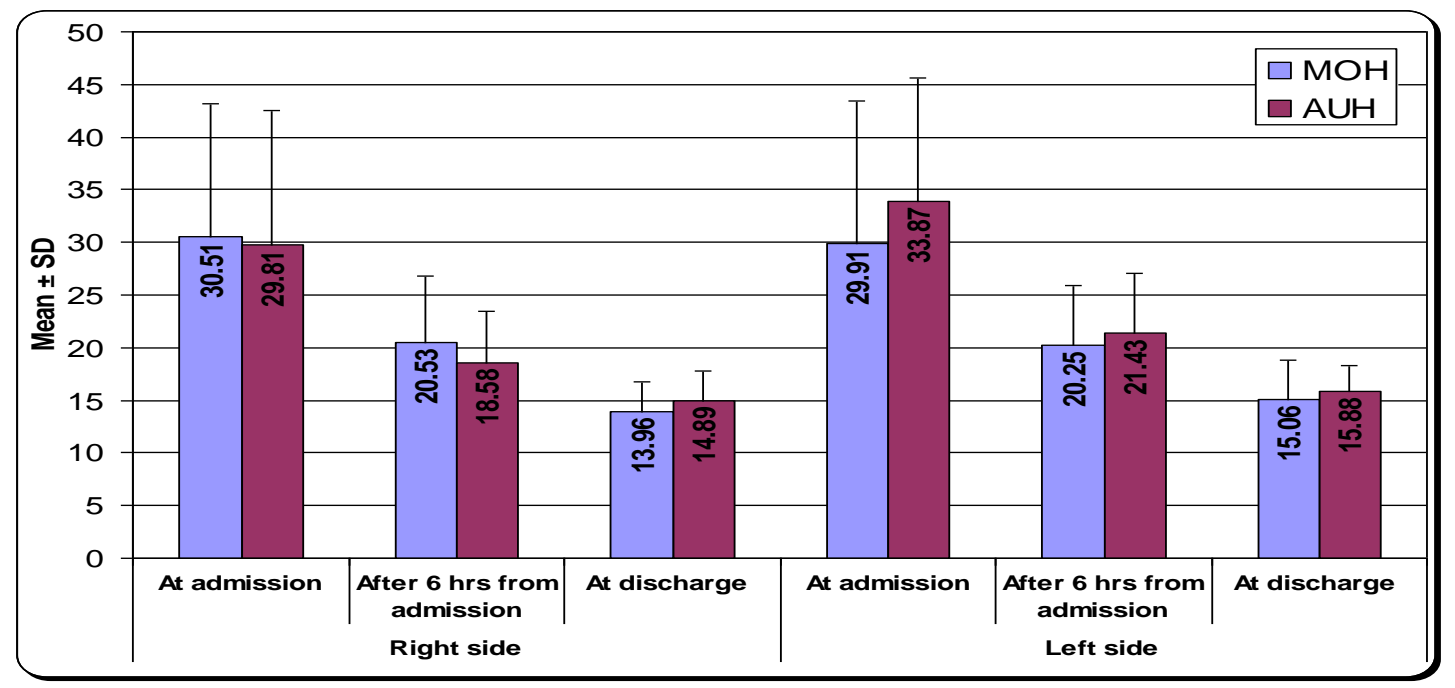

Figure (1):Show that the Mean \pm SD of intraocular pressure of the study group with (AACG) before, during, and at discharge. 


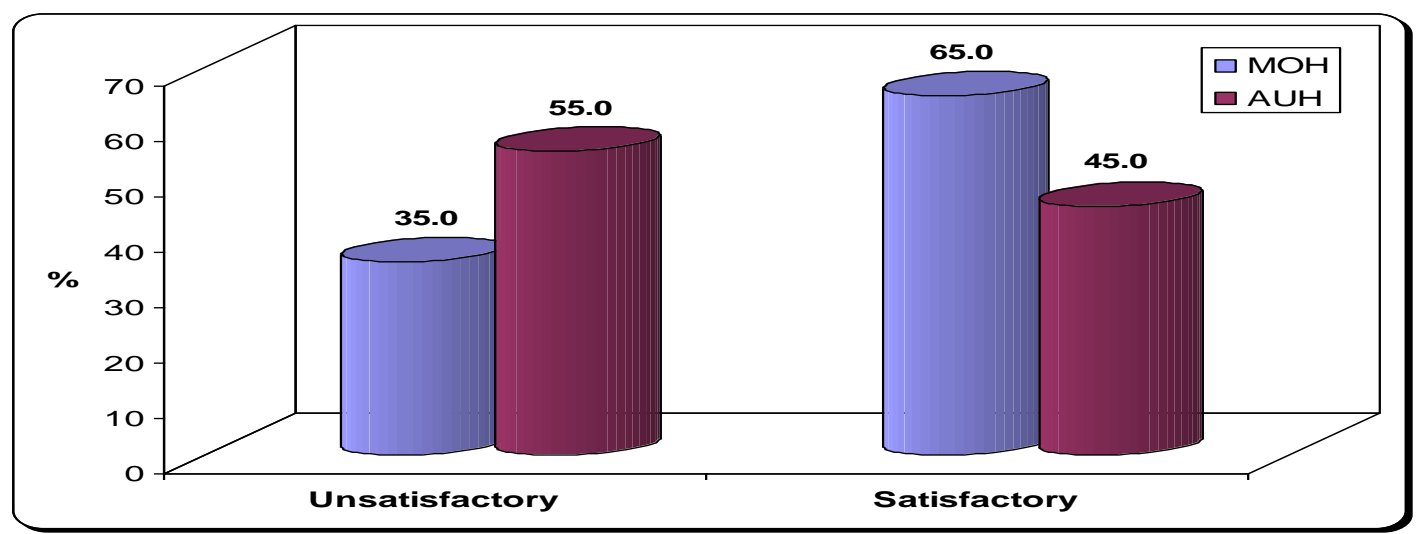

Figure (2): percentage distribution of patients' knowledge about AACG regarding intra ocular pressure (IOP), visual acuity and pain score at discharge.

Table (1): This table shows demographic characteristics of the studied groups. It showed that $67.5 \%$ of cases, aged $\geq 60$ years, $82.5 \%$ of cases were married, and $62.5 \%$ were females. As regard the level of education, residence\& occupation the study showed that $95.0 \%$ were residents of rural areas, 80.0 $\%$ were illiterate, and $90 \%$ of them were unemployed. The study also showed that $92.5 \%$ of cases have no health insurance. It was observed $100 \%$ ofthem did not receive training program about care for patients with acute angle closure glaucoma.

Table (2): Shows the mean and standard deviation of pain score at admission in the studied groups $\mathrm{MOH}$ $(7.78 \pm 1.40)$ andAUH $(7.85 \pm 1.10)$ and After 6 hrs. After admission Mean \pm SD in $\mathrm{MOH}(5.08 \pm 1.53)$ andAUH $(5.15 \pm 1.08)$ and Mean \pm SD at dischargein the studied groups $\mathrm{MOH}(2.35 \pm 1.12)$ andAUH $(2.33$ \pm 0.92 ). As regard to all shifts, results revealed that there was a no statistically significant difference between the studied groups $\left(\mathbf{P}\right.$-value ${ }^{1}=0.791,0.800$, 0.913 ), but showed significant difference between studied groupsat admission and after $6 \mathrm{hrs}$. After admission inthe study sample $\left(\mathbf{P}\right.$-value ${ }^{2}=0.000 *$, $\left.0.000^{*}\right)$ and after $6 \mathrm{hrs}$. After admissionand at discharge (P-value $\left.{ }^{3} 0.000^{*}, 0.000^{*}\right)$ respectively.

Table (3): Visual acuity has significantdifferencesbetweenstudied groups before and after treatment at p-value $(0.002,0.023$, and $0.001)$ respectively.

Figure (1): This figure illustrated that there was significant relation between the studied groups. Regarding IOP, it was found that there was a statistical significant difference between studied group's right eye in all period of follow up (At admission, after $6 \mathrm{hrs}$. from admission, andat discharge) (P-value 0.806, 0.124, 0.147) respectively. It was noticed that there was a statistical significant difference between studied groups in left eye in all period of follow up (At admission, After 6 hrs. from admission, andat discharge) (P-value 0.165, 0.351, $0.247)$ respectively.

Figure (2): This figure illustrated that $65.0 \%$ of the studied sample had a satisfactory level of knowledge with mean \pm SD11.25 \pm 2.43 and P-value 0.072. Only more than one quarter $35 \%$ of the studied patient had unsatisfactory level of knowledge at discharge.

\section{Discussion}

Acute angle closure glaucoma (AACG) is an ocular emergency and receives distinction due to its acute presentation, need for immediate treatment, and wellestablished anatomic pathology. Rapid diagnosis, immediate intervention, and referral can have profound effects on patient outcome and morbidity (Freedman \& Steven, 2012).

The present study aimed toassess the effect of immediate implementing standardized nursing care on outcomes of patients' with "Acute angle-closure glaucoma.

The findings of the present study showed that more than two thirds of the studied groups aged more than 60 years and only one third of the studied group aged less than 60 years. As regard sex, two-thirds of the studied groups were females. In addition, this study revealed that there was no significant difference between male and female.

These study results agreed with (Leske et al., 2007) who found that there was not statistically significant difference regarding gender.

Regarding to marital status of the study participants it was estimated that the majority of patients were married followed by widow, single and divorced. This study result agreed with (Onunkwor \& Monareng, 2012), who found that the majority of studied sample were married. Our study showed that most of our patients were from rural area (95\%).

Regarding the historyof the medical disordersamong the studied sample, the vast majority of patients 
(92\%) had recurrent episode of acute angle closure glaucoma followed by $(87.5 \%)$ of were having diabetes.

According to pain score, of the studied groups in all shifts, results revealed that there was no statistically significant difference between Ministry ophthalmic hospital and Assuit university hospital sample (Pvalue $\left.^{1}=0.791,0.800,0.913\right)$.

The present study showed significant difference between studied groups in admission and after six hours inthe study sample $\left(\boldsymbol{P}\right.$-value $\left.\boldsymbol{e}^{2}=0.000^{*}, 0.000 *\right)$, also the studied groups after six hours after admission there were statistical significant difference between each at discharge (P-value $\boldsymbol{P}^{3}$ 0.000*, 0.000*) respectively.

Our results were consistent with the work done by International Glaucoma Association (IGA) (2013) who stated that pain was rapidly progressive and may be confined to the eye but more usually spreads around the orbit with an associated frontal or generalized headache.

These results of our work were similar to Mary. (2015); Royal National Institute of Blind People (RNIB)(2014) who described the pain of AACG as sudden, severe pain within eye and an ache around eye, which can spread around head, the patient's eye usually feels hard and tender. The symptoms usually continue to worsen unless treated and should seek help immediately. The attack of acute angle closure glaucoma can last for a few hours and then symptoms can improve again. However, attacks will usually happen again and, with each attack, in case you need treatment to prevent a more severe attack.

It was clear from the present study that intra ocular pressure of the patients declined from $30.51 \pm 12.71$ on admission to(20.53 \pm 6.25) after $6 \mathrm{hrs}$. afteradmission, and to $(13.96 \pm 2.77)$ at discharge. It shows the benefit from the application of the standardized nursing care.

According to distribution of the increasement in intraocular pressure for acute angle closure glaucoma, there was a statistically significant difference between the studied groups in right and left eye during admission and discharge in $\mathrm{P}$ value $^{2}$,and $\mathrm{P}$-value ${ }^{3}$. It explains that all patients responded to medical and nursing management in both groups.

Visual acuity of more than two thirds of the studied patients had improved at discharge. This is explained by the effective and prompt protocol of management of AACG in our hospitals.

Our findings were consistent with Sun et al., 2010 who found that the outlook is excellent with full recovery if the diagnosis and treatment are prompt.

These results agreed with ActaClin Croat, (2008)who found that According to visual acuity before, after treatment were associated with earlier hospital admission, and depended on age. Unsatisfactory visual results despite apparently good intraocular pressure response were found in patients with late presentation for more than two days. The best visual acuity was obtained in those cases that were admitted with the onset symptom start. No statistically significant association was found in our or other similar studies between acute angle-closure glaucoma and seasonal variation.

In the current study, it was observed that three quarters of patients had satisfactory level of knowledge regarding AACG at discharge.which wasconsistent with the work done by (Onunkwor $\&$ Monareng, 2012), Who implemented a study to assess patient's knowledge about acute angle closure glaucoma in Abuja and found that the majority of respondents had good knowledge about acute angle closure glaucoma while only $14.5 \%$ of the respondents had very little or no knowledge regarding acute angle closure glaucoma.

And also our findings were consistent with(Krishnaiah et al., 2009) who carried out a study to assess population awareness about acute angle closure glaucoma in rural area of Southern India, and found that patients in rural area are aware of the disease after implementation of his study.

In the present study, it was found that the results of the patients from Ministry Ophthalmic Hospital and Assiut University hospital are nearly the same this may be attributed to the standardized nursing care given by researcher which applied the same nursing care for both groups. In addition tosome members of medical staff from Assiut University hospital who presented and give seminars to medical and nursing staff members of Ministry Ophthalmic Hospital.

Finally, it can be concluded that, developing and implementing a standardized nursing care on acute angle closure glaucoma patients' outcomes achieved its objectives by improving patient knowledge. The critical care nurses must constantly seek better ways to improve their care provided to patient, through implementing the developed standards of practice to ensure quality of care and self-satisfaction in a way that they can improve their profession and they should update these standards frequently.

\section{Conclusion}

Based on the results of the present study, it can be concluded that:

Two-thirds of the studied groups were females, and there was no significant difference between male and female.

The majority of the studied samples were from rural area. As regard pain score, the present study showed 
significant difference between studied groups on admission and after six hours inthe study samples.

There was a statistical significant difference in IOP between studied groups in right and left eye on admission and at discharge. Patients had satisfactory level of knowledge about acute angle-closure glaucoma. There was no statistically significant difference between knowledge score ofthe studied sample and their demographic characteristics.

\section{Recommendations}

Thefollowing recommendations were drawn based on the results of the present study

- Screening all people aged 40 years or more for symptoms \&signs of glaucoma.

- Health education programs about standardized nursing care rules for acute angle closures glaucoma should be implemented for nursing staff.

- Periodic health education programs should be implemented for patients in theoutpatient clinic with acute angle closures glaucoma.

- Finally, further studies should be conducted about acute angle closure glaucoma for people at any age.

\section{References}

1. ActaClin Croat (2008):visual acuity and acute angle-closure glaucoma in split - Dalmatia. Journal article university departments of ophthalmology, split university; 47 (3): 137-140

2. Agnes Lee MPhil, Bsc (Hons), PGCE, DipN, RN, RM, OND(2006).

3. Ahmed Al MoatasemKotb (2014): MedPulse International Medical Journal, pp 25-26

4. Allison W., Richard, Andrew A., Dahl, \& Robert J., Noecker, (2013):Acute AngleClosure Glaucoma

5. American Nurses Association. (2013). Nursing: Scope and Standards of Practice. Washington, DC: American Nurses Association.

6. Attia J., Ray J., Cook D., Douketis J., Ginsberg J., \& Gearts W., (2010) Prophylaxis of venous thromboembolism in the critical ill. Arch Intern; 161: 1268-79.

7. Chen Y., Chien KH1, Lu D., Cheng J., \& Chen J., (2010): Relief of periorbital pain after acute angle closure glaucoma attack by botulinum toxin type A.

8. Dahl A., (2013): Acute angle-closure glaucoma.eMedicineHealth. Retrieved on Aug. 26, 2013, from emedicinehealth.

9. Egyptian Society for glaucoma disease,(2011): The treatment and diagnosis of glaucoma, the world's leading cause of irreversible blindness.
10. Freedman Joseph, (2012): \& Steven CDronen, FAAEM ('authordisclosures');" Updated: Oct 30, 2012.

11. Green M., (2011): Cheerio, Laddiee, Bidding Farewell to the Glasgow Coma Scale. Annals of Emergency Medicine; 58 (5): 427-430.

12. Heiting G., (April 2010.) Narrow-angle glaucoma.All about Vision. Retrieved on Aug. 26, 2013, from www.allaboutvision.com/conditions/narrowangle-glaucoma.htm

13. International Glaucoma Association, 2013; (Royal National Institute of Blind People 2014).

14. Kanski J., Jack (2013): Synopsis of clinical ophthalmology .J Primary angle -closure glaucoma $3^{\text {rd }}$ ed., (9):p.159-162.

15. Krishnaiah, S., Kovai, Srinivas, M., Shamanna, R., Rao, \& Thomas, R., (2009): Awareness of glaucoma in the rural population of Southern India, Community Ophthalmology, volume53, issue3, page 205-208.

16. Lesk M., Wu S., \& Honkanen R., (2007): Nine-year incidence of open-angle glaucoma in the Barbados Eye Studies. Ophthalmology 114:1058-1064.

17. Nicol M., Bavib C., Cronin P., Anderson K., \& Cole E., et al., (2012):Nursing skills clinical skills for caring patients, $4^{\text {th }}$ edition, Ch. 2 ,p.p68,69,157,London, Mosby company.

18. Onunkwor, C., \& Monareng, L., (2012): glaucoma Knowledge of patients in Abuja, Nigeria Africa journal of nursing \&midwifery; vol. 14 issue $1, \mathrm{p} 3$

19. Royal National Institute of Blind People (RNIB) \& International Glaucoma Association (IGA), 2014.

20. Shojania K., Duncan B., McDonald K., wachter R., Markowiz A., (2010): Making health care safer a critical analysis of patient safety practice. Agency for healthcare research and quality (US).

21. Sun X., Liang Y., Wang N., Fan S., Sun L., \& Li S., (2010): Laser peripheral iridotomy with and without iridoplasty for primary angle-closure glaucoma: 1-year results of a randomized pilot study. Am J Ophthalmol ; 150(1):68-73.

22. Tasman W., \& Jaeger E., ( 2013): The Optic Nerve in Glaucoma. In: eds. Duane's Ophthalmology. ed. Philadelphia, Pa: Lippincott Williams \& Wilkins; vol 13, chaps 48. 